\title{
Pipeline embolization device versus coiling for the treatment of large and giant unruptured intracranial aneurysms: a cost-effectiveness analysis
}

\author{
*Arvin R. Wali, BA, ${ }^{1}$ Charlie C. Park, BS, ${ }^{2}$ David R. Santiago-Dieppa, MD, ${ }^{1}$ Florin Vaida, $\mathrm{PhD},{ }^{3}$ \\ James D. Murphy, MD, ${ }^{4}$ and Alexander A. Khalessi, MD ${ }^{1}$ \\ Departments of ${ }^{1}$ Neurological Surgery, ${ }^{2}$ Radiology, ${ }^{3}$ Bioinformatics and Biostatistics, and ${ }^{4}$ Radiation Medicine and Applied \\ Sciences, University of California, San Diego, California
}

\begin{abstract}
OBJECTIVE Rupture of large or giant intracranial aneurysms leads to significant morbidity, mortality, and health care costs. Both coiling and the Pipeline embolization device (PED) have been shown to be safe and clinically effective for the treatment of unruptured large and giant intracranial aneurysms; however, the relative cost-to-outcome ratio is unknown. The authors present the first cost-effectiveness analysis to compare the economic impact of the PED compared with coiling or no treatment for the endovascular management of large or giant intracranial aneurysms.

METHODS A Markov model was constructed to simulate a 60-year-old woman with a large or giant intracranial aneurysm considering a PED, endovascular coiling, or no treatment in terms of neurological outcome, angiographic outcome, retreatment rates, procedural and rehabilitation costs, and rupture rates. Transition probabilities were derived from prior literature reporting outcomes and costs of PED, coiling, and no treatment for the management of aneurysms. Cost-effectiveness was defined, with the incremental cost-effectiveness ratios (ICERs) defined as difference in costs divided by the difference in quality-adjusted life years (QALYs). The ICERs $<\$ 50,000 / Q A L Y$ gained were considered cost-effective. To study parameter uncertainty, 1-way, 2-way, and probabilistic sensitivity analyses were performed.

RESULTS The base-case model demonstrated lifetime QALYS of 12.72 for patients in the PED cohort, 12.89 for the endovascular coiling cohort, and 9.7 for patients in the no-treatment cohort. Lifetime rehabilitation and treatment costs were $\$ 59,837.52$ for PED; $\$ 79,025.42$ for endovascular coiling; and $\$ 193,531.29$ in the no-treatment cohort. Patients who did not undergo elective treatment were subject to increased rates of aneurysm rupture and high treatment and rehabilitation costs. One-way sensitivity analysis demonstrated that the model was most sensitive to assumptions about the costs and mortality risks for PED and coiling. Probabilistic sampling demonstrated that PED was the cost-effective strategy in $58.4 \%$ of iterations, coiling was the cost-effective strategy in $41.4 \%$ of iterations, and the no-treatment option was the cost-effective strategy in only $0.2 \%$ of iterations.
\end{abstract}

CONCLUSIONS The authors' cost-effective model demonstrated that elective endovascular techniques such as PED and endovascular coiling are cost-effective strategies for improving health outcomes and lifetime quality of life measures in patients with large or giant unruptured intracranial aneurysm.

https://thejns.org/doi/abs/10.3171/2017.3.FOCUS1749

KEY WORDS cost-effectiveness; intracranial aneurysm; endovascular neurosurgery; Pipeline embolization device; coil embolization

$\mathrm{T}$ REATMENT of large or giant intracranial aneurysms remains difficult despite advances in endovascular management. ${ }^{26}$ Patients with a large intracranial aneurysm are subject to increased risk of spontaneous rupture with poor neurological outcome after subarachnoid hemorrhage. ${ }^{14,23}$ With advances in endovascular technology, novel techniques to manage large or giant intracranial aneurysm have emerged. The role of the Pipeline embolization device (PED; Covidien) in the management of large or giant intracranial aneurysms has become increasingly established as retrospective and prospective studies demonstrate its clinical safety and efficacy. ${ }^{2,3}$ A prior study comparing the

ABBREVIATIONS ICER = incremental cost-effectiveness ratio; ISAT = International Subarachnoid Aneurysm Trial; mRS = modified Rankin scale; PED = Pipeline embolization device; $\mathrm{QALY}=$ quality-adjusted life year; $\mathrm{QOL}=$ quality of life.

SUBMITTED February 1, 2017. ACCEPTED March 22, 2017.

INCLUDE WHEN CITING DOI: 10.3171/2017.3.FOCUS1749.

* Mr. Wali and Mr. Park contributed equally to this work. 


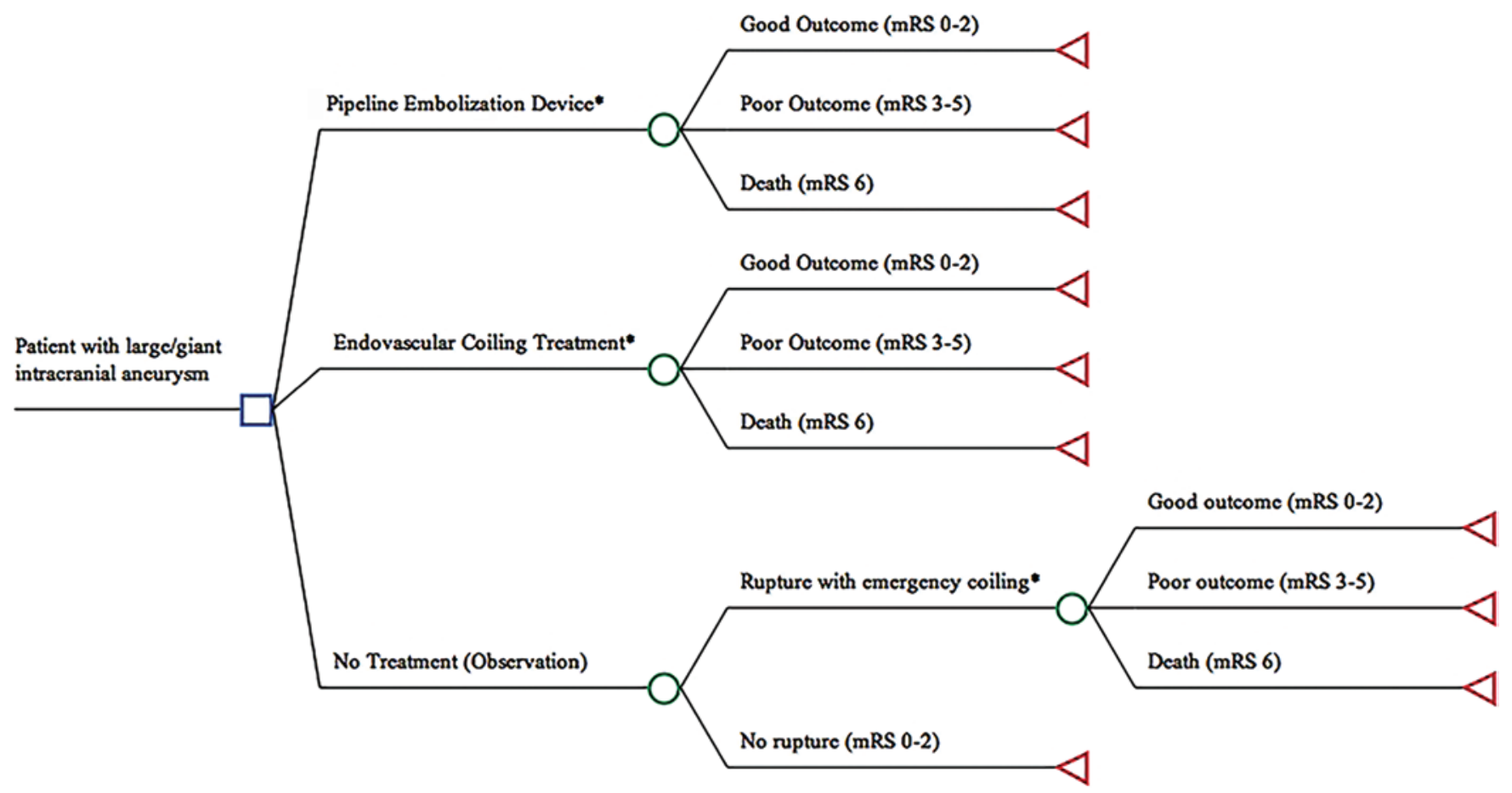

FIG. 1. Decision analysis model with competing strategies for endovascular management of a patient with a large or giant intracranial aneurysm. The square decision node indicates the 3 options: to undergo Pipeline embolization of the aneurysm, to undergo endovascular coiling of the aneurysm, or to undergo no treatment and be subject to risk of spontaneous rupture. The asterisks denote that, after undergoing either elective or emergency intervention, patients may require subsequent retreatment, which would contribute to additional procedural costs. Patients also may have either complete or incomplete angiographic occlusion. Patients with incomplete angiographic occlusion despite initial treatment are at risk for rupture.

efficacy of PED versus endovascular coiling, the standard endovascular technique to treat aneurysms, has demonstrated comparable neurological outcomes in patients. ${ }^{6} \mathrm{Im}-$ portantly, PED use in giant intracranial aneurysms may be associated with lower overall procedural cost and higher rates of complete angiographic occlusion. ${ }^{9}$

Although the comparative efficacy and procedural costs of these emerging endovascular techniques have been described, a cost-effectiveness analysis to demonstrate the lifetime health utility and economic impact of endovascular techniques compared with no treatment has not yet been conducted. We present the first cost-effectiveness model to directly compare PED, endovascular coiling, and no treatment to determine the cost-effectiveness of each strategy to manage large or giant intracranial aneurysms. Incremental cost-effectiveness ratios (ICERs) were used to assess the strategies. This model highlights the economic and quality of life (QOL) outcome of these novel endovascular treatment techniques.

\section{Methods}

\section{Treatment Strategies}

Our decision model captures the choice for a patient with an identified, nonsurgically resectable, large or giant intracranial aneurysm who is deciding between PED, coiling, and no treatment. We chose a nonsurgically resectable aneurysm to best evaluate the cost-effectiveness of endovascular aneurysm treatments. The treatment choices for a large, unruptured intracranial aneurysm were as follows:
Strategy 1 was PED treatment; Strategy 2, endovascular coiling; and Strategy 3, no endovascular treatment.

\section{Decision Model}

A decision-analysis Markov model was constructed to assess the cost-effectiveness of PED, endovascular coiling, and no treatment in patients with a confirmed large or giant intracranial aneurysm that was not amenable to resection. The decision-analytical model incorporated patient QOL, survival, and costs associated with each treatment. The base-case model simulates outcomes for a 60 -yearold woman with a large or giant intracranial aneurysm (> $10 \mathrm{~mm}) .^{2}$ The Markov model was constructed with an annual cycle length, and it was run over a 50 -year time horizon to capture the long-term implications of these 3 treatment strategies. Our model assumed a risk of death from the treatments, and a risk of aneurysm rupture (described further below), and it also assumed an underlying age-specific risk of death from other causes that was derived from the Centers for Disease Control and Prevention mortality data. ${ }^{1}$ A simplified decision analysis model is illustrated in Fig. 1.

\section{Model Inputs \\ Neurological Outcomes}

The modified Rankin scale (mRS) represents the primary tool to measure neurological outcomes associated with the different treatment strategies. We converted the reported mRS values into health utility scores by using 
TABLE 1. Neurological outcome (mRS score) by health utility score (QALYs) in reports of patients with large or giant unruptured aneurysms

\begin{tabular}{ccccc}
\hline Variable Name & $\begin{array}{c}\text { Health } \\
\text { Utility }\end{array}$ & SD & Distribution & Authors \& Year \\
\hline $\begin{array}{c}\text { mRS Score 0-2, } \\
\text { PED/coil }\end{array}$ & 0.851 & 0.18 & Beta & $\begin{array}{c}\text { Rivero-Arias et al., } \\
\text { 2010; Chalouhi } \\
\text { et al., 2013 }\end{array}$ \\
\hline $\begin{array}{c}\text { mRS Score 3-5, } \\
\text { PED/coil }\end{array}$ & 0.478 & 0.24 & Beta & $\begin{array}{c}\text { Rivero-Arias et al., } \\
\text { 2010; Chalouhi } \\
\text { et al, 2013 }\end{array}$ \\
\hline $\begin{array}{c}\text { mRS Score 0-2, } \\
\text { emergency } \\
\text { treatment }\end{array}$ & 0.81 & 0.21 & Beta & $\begin{array}{c}\text { Molyneux et al., } \\
2005\end{array}$ \\
\hline $\begin{array}{c}\text { mRS Score 3-5, } \\
\text { emergency } \\
\text { treatment }\end{array}$ & 0.41 & 0.32 & Beta & $\begin{array}{c}\text { Molyneux et al., } \\
2005\end{array}$ \\
\hline
\end{tabular}

techniques described elsewhere. ${ }^{3}$ Distributions of mRS outcomes for each endovascular treatment option including emergency coiling for a ruptured aneurysm were obtained from the current literature. The individual mRS outcomes for patients were grouped into good outcome (mRS Score 0-2), poor outcome (mRS Score 3-5), and death (mRS Score 6) based on reported conventions for outcome after aneurysm treatment by Chalouhi et al. ${ }^{6}$ Postoperative complications such as procedural stroke, aneurysm rupture, or hemorrhage that caused permanent deficits were incorporated into our model if they caused long-term neurological deficits resulting in either poor $\mathrm{mRS}$ outcome or death. To model the proportions of patients who had a unique mRS score within the good and poor outcome groups, a negative binomial distribution was constructed to model the proportion of patients within each mRS state ranging from 0 to 6 , and estimated the parameters separately for each study by using the maximum likelihood method., ${ }^{1,4}$ The final health utility scores incorporated within the model correspond to the predicted probabilities of this negative binomial distribution (Table 1).

\section{Model Probabilities}

\section{The mRS Outcomes by Type of Treatment}

At the initiation of the model prior to any intervention, all patients were assumed to have good baseline neurological status (mRS Score 0-2). We incorporated the risk of aneurysmal rupture for untreated patients from large prospective randomized studies, which report an annual rupture rate of $7 \%$ for aneurysms $>10 \mathrm{~mm}$ and an annual rupture rate of $43 \%$ for aneurysms $>25 \mathrm{~mm} .{ }^{14}$ To capture the patient population assessed by Chalouhi et al. in which patients underwent either PED or endovascular coiling, and in which $20 \%$ of patients had aneurysms $>20 \mathrm{~mm}$ and $80 \%$ had aneurysms between 10 and $20 \mathrm{~mm},{ }^{9}$ our model assumed a rupture rate of $13 \%$ for both groups within our base-case analysis.

Prior published data from Chalouhi et al. comparing PED with endovascular coiling to treat large, unruptured intracranial aneurysms reported a $92 \%$ probability of achieving a good $\mathrm{mRS}$ score, a $5.4 \%$ probability of achieving a poor mRS score, and a $2.6 \%$ probability of death at 8-month follow-up. ${ }^{6}$ These findings were comparable to a larger prospective study by Becske et al. that assessed outcome rates at 3-year follow-up of PED management for large intracranial aneurysms in which $92 \%$ had good outcome, $3.5 \%$ had a poor outcome, and $4.5 \%$ died. ${ }^{3}$ Given the comparable rates between these 2 studies, our model used the mRS outcomes from Chalouhi et al. as a similar study population to compare with the endovascular coiling group. For endovascular management, which included conventional coiling, stent-assisted coiling, and balloon-assisted coiling, Chalouhi et al. reported $94 \%$ of patients with a good outcome (mRS Score 0-2), 6\% with a poor outcome (mRS Score 3-5), and 0 deaths at 15-month follow-up. ${ }^{9}$ Other studies reported a $1.25 \%$ mortality rate associated with coiling for unruptured aneurysms. ${ }^{29}$ To account for some probability of death within the model, we assumed that the final distribution of mRS scores after treatment with endovascular coiling was $94 \%$ with a good outcome, $4.75 \%$ with a poor outcome, and $1.25 \%$ with death.

Neurological outcome after spontaneous rupture of aneurysms that underwent subsequent emergency treatment was derived from the landmark International Subarachnoid Aneurysm Trial (ISAT), in which $76.5 \%$ of patients had mRS scores of $0-2,15.5 \%$ had mRS scores of 3-5, and $8 \%$ died. ${ }^{21}$ Although the ISAT did not emphasize the emergency treatment of large or giant aneurysms specifically, these outcome values are similar to the existing reports in the literature that describe mRS outcome at 1-year follow-up after rupture of a large or giant intracranial aneurysm with endovascular treatment, and thus are used within our model. ${ }^{11,12,16,17,19}$ The probabilities of good outcome, poor outcome, and death after rupture of a previously treated aneurysm were also based on outcomes from the ISAT. ${ }^{20,21}$ Our model assumed that patients with major disability (mRS Score 3-5) after initial treatment who had a subsequent aneurysm rupture either still had a poor outcome (mRS Score 3-5) or died-these patients had a 66\% chance of remaining at $\mathrm{mRS}$ Score $3-5$ and a $34 \%$ chance of death following rupture. ${ }^{20,27}$

\section{Angiographic Outcomes by Type of Treatment}

Chalouhi et al. reported that within the 1st year of treatment with either PED or endovascular coiling, 2.8\% of those undergoing PED required additional treatment with coiling, whereas $37 \%$ of patients initially treated with coiling required subsequent recoiling. ${ }^{6}$ Chalouhi et al. reported that $86 \%$ of patients treated with PED had complete angiographic occlusion at 7 months. Given that occlusion rates after PED treatment increased over time ${ }^{28}$ and that the angiographic outcome reported by Chalouhi et al. was similar to complete occlusion rates at a follow-up of $>1$ year, these values were included within our model. ${ }^{3}$ Chalouhi et al. report that, following endovascular coiling, $41 \%$ of patients attained complete occlusion at 12-month followup. Patients who had incomplete angiographic occlusion of their aneurysm were subject to an annual rupture risk of $4.3 \% .{ }^{15}$ Our model assumed that patients who had aneurysmal rupture and emergency endovascular coiling were subject to the same retreatment and angiographic occlu- 
TABLE 2. Decision analysis model probabilities and patient characteristics in reports of large or giant unruptured aneurysms

\begin{tabular}{|c|c|c|c|c|}
\hline Variable Value & Value & SD & Distribution & Authors \& Year \\
\hline Patient age in yrs & 60 & 10 & Binomial & Chalouhi et al., 2013 \\
\hline \multicolumn{5}{|l|}{ Aneurysm rupture rates } \\
\hline Annual rupture risk for large or giant aneurysm w/o treatment & $13 \%$ & $2.6 \%$ & Beta & Ishibashi et al., 2009 \\
\hline Annual rupture risk w/ incomplete angiographic occlusion & $4.3 \%$ & $0.9 \%$ & Beta & Johnston et al., 2008 \\
\hline Good outcome (mRS Score 0-2) after spontaneous rupture w/ good mRS baseline & 0.765 & 0.153 & Beta & Molyneux et al., 2005 \\
\hline Poor outcome (mRS Score 3-5) after spontaneous rupture w/ good mRS baseline & 0.155 & 0.414 & Beta & Molyneux et al., 2005 \\
\hline Death (mRS Score 6) after spontaneous rupture w/ good mRS baseline & 0.08 & 0.016 & Beta & Molyneux et al., 2005 \\
\hline Poor outcome (mRS Score 3-5) after spontaneous rupture w/ poor mRS baseline & $0.66^{*}$ & 0.13 & Beta & Molyneux et al., 2005 \\
\hline Death (mRS Score 6) after spontaneous rupture w/ poor mRS baseline & $0.34^{*}$ & 0.06 & Beta & Molyneux et al., 2005 \\
\hline \multicolumn{5}{|l|}{ PED treatment } \\
\hline Good outcome (mRS Score $0-2$ ) after PED & 0.92 & 0.184 & Beta & Chalouhi et al., 2013 \\
\hline Poor outcome (mRS Score 3-5) after PED & 0.053 & 0.01 & Beta & Chalouhi et al., 2013 \\
\hline Death (mRS Score 6) after PED & 0.026 & 0.005 & Beta & Chalouhi et al., 2013 \\
\hline Probability of PED requiring endovascular retreatment & 0.028 & 0.005 & Beta & Chalouhi et al., 2013 \\
\hline Probability of complete angiographic occlusion w/ PED & 0.86 & 0.172 & Beta & Chalouhi et al., 2013 \\
\hline \multicolumn{5}{|l|}{ Endovascular coiling } \\
\hline Good outcome after endovascular coiling & 0.94 & 0.02 & Beta & Chalouhi et al., 2013; Yue, 2011 \\
\hline Poor outcome after endovascular coiling & 0.047 & 0.007 & Beta & Chalouhi et al., 2013; Yue, 2011 \\
\hline Death after endovascular coiling & 0.012 & 0.005 & Beta & Chalouhi et al., 2013; Yue, 2011 \\
\hline Probability of coiling requiring endovascular retreatment & 0.37 & 0.074 & Beta & Chalouhi et al., 2013 \\
\hline Probability of complete angiographic occlusion w/ coiling & 0.41 & 0.082 & Beta & Chalouhi et al., 2013 \\
\hline
\end{tabular}

* Refers to estimated values at which patients who had prior poor neurological status and who had aneurysm rupture would either remain at their poor neurological status or die.

sion rates as with elective coiling. Our model also assumed complete angiographic occlusion after emergency retreatment of a previously treated aneurysm. All probabilities, angiographic outcomes, rupture rates, and retreatment rates are detailed in Table 2.

\section{Treatment Costs}

The costs of endovascular coiling (which averaged the costs of stent-assisted coiling, balloon-assisted coiling, and conventional coiling) and the costs for PED were derived from published literature describing the treatment of large or giant intracranial aneurysms.9 The costs of PED and coiling were consistent with previously reported findings in the literature demonstrating that the overall procedural costs of PED were lower relative to elective coiling.? Costs of emergency coiling and associated hospitalization fees were derived from a prior cost-effectiveness study assessing the role of endovascular coiling in treating ruptured aneurysms. ${ }^{18}$ The cost of endovascular retreatment after initial intervention was equivalent to the entire procedure cost associated with endovascular coiling. All interventional costs also consisted of additional procedural costs of intraoperative and postoperative angiograms. ${ }^{18}$ Indirect costs to account for the management of functional disability were derived from a prior cost-effectiveness study on rehabilitation and special nursing facility costs associated with each mRS score. ${ }^{22}$ All retrospectively obtained costs from the literature were converted to 2016 US dollars to account for inflation (https://data.bls.gov/cgi-bin/cpicalc. pl). All costs in the model are detailed in Table 3.

\section{Cost-Effectiveness Analysis}

TreeAge Pro 2016 (TreeAge Software) was used to construct the decision analysis model. Our model discounted utilities and costs by $3 \%$ annually. ${ }^{13}$ Cost-effectiveness between the different treatments was assessed using the ICER, which represents the difference in costs divided by the difference in quality-adjusted life years (QALYs) between the treatment arms. Results were considered costeffective if the ICER was less than a willingness-to-pay cutoff of \$50,000/QALY - a convention used in cost-effectiveness analyses. ${ }^{5}$ A strategy was considered dominant within this analysis if both the costs were more and the health utility outcomes were less than a competing strategy. The cost-effectiveness results are presented from a societal viewpoint.

The base-case analysis represents the cost-effectiveness analysis using our best estimation of all parameters in the model. In addition to the base-case analysis we conducted 1-way, 2-way, and probabilistic sensitivity analyses. The 1-way sensitivity analyses were performed on all variables in the model, although we present only variables that the model was most sensitive to, including changes in patient age, probability of spontaneous rupture, cost of PED, and cost of coiling. Probabilistic sensitivity analysis consisted of a Monte Carlo simulation that included 100,000 iterations, which sampled from model parameters fit to individual probability distributions. ${ }^{8}$ In the probabilistic sensitivity analysis, age was modeled as a binomial distribution, costs were modeled by gamma distributions (constrained between 0 and infinity), and probabilities and 
TABLE 3. Costs incorporated within the model in reports of patients with large or giant unruptured aneurysms*

\begin{tabular}{lrrrl}
\hline \multicolumn{1}{c}{ Costs } & \multicolumn{1}{c}{ Value } & \multicolumn{1}{c}{ SD } & Distribution & Authors \& Year \\
\hline Elective Pipeline embolization & $\$ 24,995.46$ & $\$ 12,531.70$ & Gamma & el-Chalouhi et al., 2014 \\
\hline Elective endovascular coiling & $\$ 31,906.29$ & $\$ 24,861.65$ & Gamma & el-Chalouhi et al., 2014 \\
\hline Emergency endovascular intervention \& hospitalization & $\$ 41,838.13$ & $\$ 8,367.63$ & Gamma & Maud et al., 2009 \\
\hline Elective endovascular coiling retreatment & $\$ 31,906.29$ & $\$ 24,861.65$ & Gamma & el-Chalouhi et al., 2014 \\
\hline Angiogram & $\$ 894.98$ & $\$ 179.00$ & Gamma & Maud et al., 2009 \\
\hline Rehabilitation-mRS Score 0-2 for coil/PED cohort & $\$ 1,251.43$ & $\$ 250.29$ & Gamma & Nelson et al., 2011; Chalouhi et al., 2013 \\
\hline Rehabilitation-mRS Score 3-5 for coil/PED cohort & $\$ 14,405.76$ & $\$ 2,881.15$ & Gamma & Nelson et al., 2011; Chalouhi et al., 2013 \\
\hline Rehabilitation-mRS Score 0-2 for emergency treatment cohort & $\$ 1,630.06$ & $\$ 326.01$ & Gamma & Nelson et al., 2011; Chalouhi et al., 2013 \\
\hline Rehabilitation-mRS Score 3-5 for emergency treatment cohort & $\$ 57,534.23$ & $\$ 11,506.85$ & Gamma & Nelson et al., 2011; Chalouhi et al., 2013 \\
\hline
\end{tabular}

* Costs are expressed in 2016 US dollars.

health utilities were modeled as beta distributions (constrained between 0 and 1). When possible, the standard deviation of each modeled variable was obtained from the literature, although when unavailable the standard deviation was assumed to be $20 \%$ of the mean value.

\section{Results \\ Base-Case Analysis}

Our base-case cost-effectiveness model demonstrated that elective PED and endovascular coiling were more effective than no treatment, yielding 12.72 QALYs in the PED group and 12.89 QALYs in the endovascular coiling group. Lifetime treatment and rehabilitation costs in the base-case scenario were $\$ 59,800$ for PED and $\$ 79,000$ for endovascular coiling. Patients who did not undergo elective treatment had an effectiveness of 9.7 QALYs, and costs of $\$ 193,500$. Our cost-effectiveness analysis showed that although endovascular coiling provided more QALYs over a lifetime, the increased costs incurred to achieve those QALYs yielded an ICER of $\$ 123,600$ per QALY gained (Fig. 2), indicating that PED was the more cost-effective option at a willingness-to-pay threshold of $\$ 50,000$ per QALY gained.

\section{One-Way Sensitivity Analysis}

One-way sensitivity analysis demonstrated that the cost-effectiveness comparing PED and coiling was most sensitive to changes in cost of PED, cost of coiling, and probability of spontaneous death after PED (Table 4). As the initial cost of PED exceeded $\$ 40,100$, coiling became the more cost-effective option at a willingness-to-pay threshold of $\$ 50,000 /$ QALY. When the initial procedural cost of coiling decreased to $\$ 21,200$, coiling would be considered the more cost-effective option. As the probability of initial death after PED increased beyond 4\%, coiling became the more cost-effective option. Across the ranges tested for treatment costs, none of the sensitivity analyses demonstrated the no-treatment arm to be a cost-effective strategy.

The PED remained the cost-effective strategy despite changes in the following variables at the range of values described: patient age from 18 to 80 years, spontaneous rupture rate of $7 \%$ (corresponding to aneurysms $>10 \mathrm{~mm}$ ) to $43 \%$ (aneurysms $>25 \mathrm{~mm}$ ), rate of achieving a good outcome with PED from $80 \%$ to $100 \%$, rate of good outcome with coiling from $94 \%$ to $100 \%$, rate of good angiographic outcome for coiling from $41 \%$ to $100 \%$, retreatment rate for coiling from $5 \%$ to $37 \%$, and rate of death with endovascular coiling from $0 \%$ to $1.25 \%$.

\section{Two-Way Sensitivity Analysis}

A 2-way sensitivity analysis was constructed to illustrate how the cost-effective strategy between PED and coiling transitioned across initial treatment costs ranging from $\$ 5,000$ to $\$ 50,000$ for either PED or coiling (Fig. $3)$. At a PED cost of $<\$ 11,200$, PED remained the costeffective strategy compared with the cost of coiling ranging up to $\$ 50,000$. At a cost of endovascular coiling $>$ $\$ 44,900$, PED was the cost-effective strategy ranging up to $\$ 50,000$.

\section{Probabilistic Sensitivity Analysis}

Figure 4 demonstrates the results of the Monte Carlo probabilistic sensitivity analysis. This analysis found that the no-treatment option was unlikely to be cost-effective across a range of willingness-to-pay thresholds compared with the 2 treatment options. When comparing PED and coiling, the probabilistic sensitivity analysis demonstrated a moderate degree of uncertainty with regard to which treatment arm was more cost-effective. At a willingnessto-pay threshold of $\$ 50,000 / \mathrm{QALY}$, the PED was the costeffective strategy in $58.4 \%$ of iterations, coiling was the cost-effective strategy in $41.4 \%$ of iterations, and the notreatment option was the cost-effective strategy in $0.2 \%$ of iterations.

\section{Discussion}

As novel endovascular techniques emerge and become increasingly prevalent in the elective management of unruptured large or giant intracranial aneurysm, it is imperative for health care decision makers and patients to be informed on the cost-effectiveness of these treatment techniques. Patients who have large or giant intracranial aneurysms are at a very high risk of rupture, ranging from $7 \%$ to $43 \%$ annually, which results in expensive emergency treatment, a high mortality rate, and a high potential for severe neurological disability. ${ }^{14}$ 


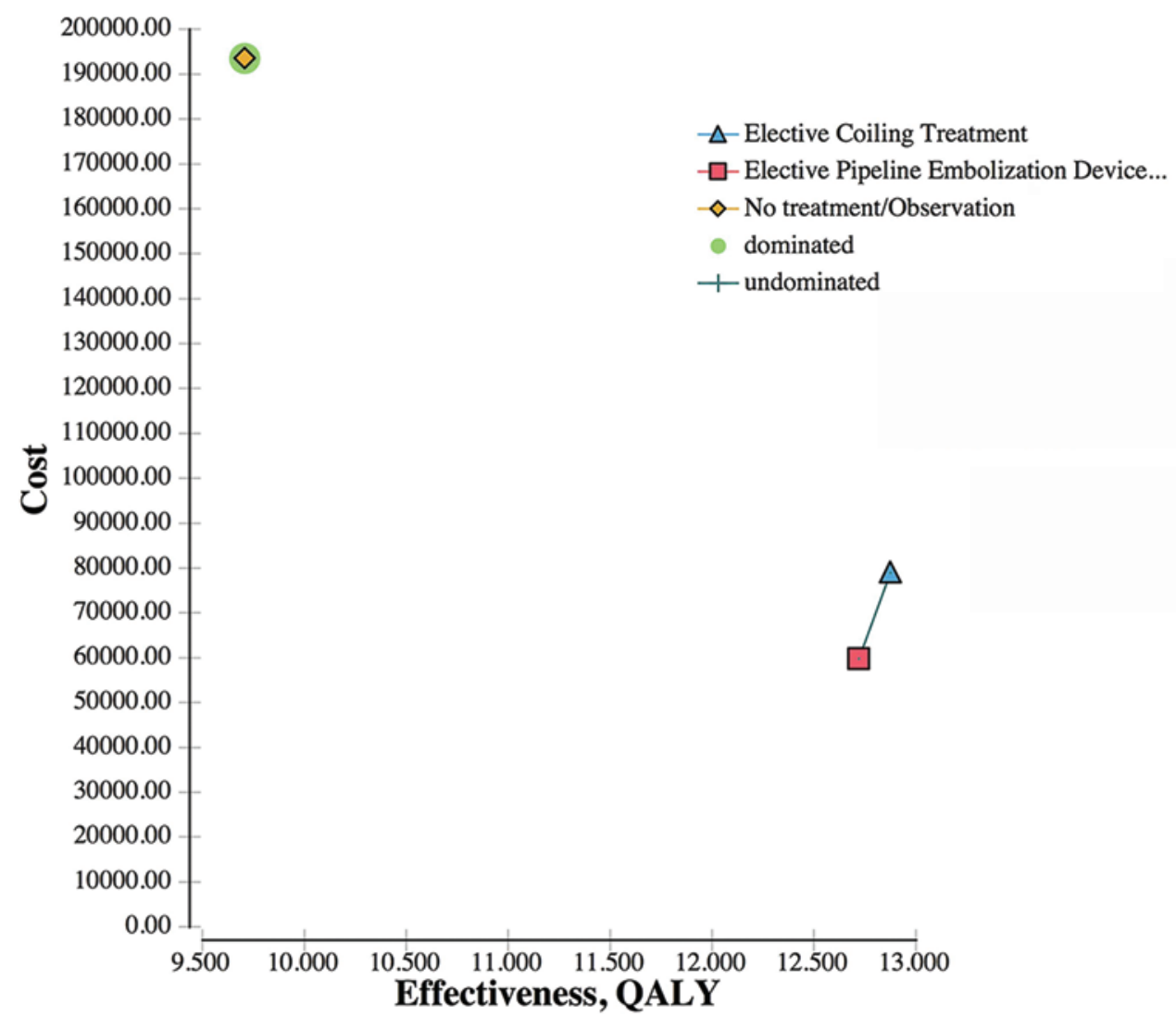

FIG. 2. Graph showing cost-effectiveness analysis demonstrating the cost and overall QALY for the competing strategies. The no-treatment strategy (yellow, highlighted in green) is shown to be dominated by elective PED and coiling treatment. The PED and coiling treatment demonstrated 12.72 QALYs and 12.89 QALYs, respectively, with an ICER of $\$ 123,600$ per QALY gained, indicating that PED was the more cost-effective strategy.

Whereas prior cost-effectiveness models have assessed neurosurgical clipping compared with endovascular coiling for emergency treatment of ruptured aneurysms ${ }^{18}$ the present work is the first cost-effectiveness study to examine the elective endovascular management of large or giant intracranial aneurysms. Our model demonstrates that both elective PED and endovascular coiling are efficacious in dramatically improving lifetime QALYs, resulting in lifetime QALYs of 12.72 and 12.89 , respectively, compared with QALYs of 9.7 in the no-treatment (observation) cohort. Although not undergoing treatment may be cost saving initially due to avoiding procedural costs, the high annual rupture rate associated with large or giant aneurysms and the subsequent ramifications, including higher costs of emergency intervention, lifetime rehabilitation, and severe neurological disability as well as elevated risk of death argue decisively in favor of aneurysm treatment provided using endovascular techniques.

Our model was sensitive to changes in the cost of PED and coiling, respectively. Chalouhi et al. reported a large variance in the cost of PED $(\$ 24,995.46 \pm \$ 12,531.70)$ and endovascular coiling $(\$ 31,906.29 \pm \$ 24,861.65) .{ }^{9}$ The costs of PED and endovascular coiling vary depending on the characteristics of the aneurysm, such as its size.? Our model demonstrated that the more cost-effective endovascular treatment strategy between PED and coiling depended on the price of each procedure across a comparable range of costs. Using the mean procedural costs in the literature, our model indicated that PED may be slightly more costeffective than coiling over a lifetime, possibly due to the decreased incidence of retreatment and higher rates of angiographic occlusion.

Notably, endovascular coiling generated 0.15 more QALYs over a lifetime compared with the PED, which would largely be ascribed to the higher initial mortality of $2.6 \%$ with the PED compared with a procedural mortality of $1.25 \%$ with endovascular coiling. Complications associated with the PED, including parent vessel thrombosis, still only represent a small fraction of patients, and the incidence of morbidity and mortality associated with the PED may decrease as technical skill and management of these patients continue to improve. ${ }^{3,10}$ Moreover, the probabilistic sensitivity analysis demonstrated that the PED was the dominant strategy in 58\% of 100,000 iterations of our model compared with endovascular coiling dominating in $41 \%$ of iterations. These rates are similar due to the comparable neurological outcomes associated with both treatment techniques. The probabilistic sensitivity analysis demonstrates slight favorability of PED over coiling given the trend toward lower procedural costs, decreased need for retreatment, and improved angiographic outcomes. The no-treatment strategy was cost-effective in only $0.2 \%$ of iterations, demonstrating the urgent and important need to electively treat an identified large or giant 
TABLE 4. One-way sensitivity analysis demonstrating changes in ICER in patients with large or giant unruptured aneurysms

\begin{tabular}{lccccc}
\hline Parameter & $\begin{array}{c}\text { Value Used for } \\
\text { Sensitivity Analysis }\end{array}$ & $\begin{array}{c}\text { ICER for } \\
\text { PED }\end{array}$ & $\begin{array}{c}\text { ICER for } \\
\text { Coiling }\end{array}$ & $\begin{array}{c}\text { ICER for No } \\
\text { Treatment }\end{array}$ & $\begin{array}{c}\text { Dominant } \\
\text { Strategy }\end{array}$ \\
\hline Initial procedural cost of PED & $\$ 5,000$ & $\mathbf{0}$ & $\$ 286,194.57$ & Dominated & PED \\
\hline & $\$ 14,000$ & $\mathbf{0}$ & $\$ 224,866.85$ & Dominated & PED \\
\hline & $\$ 23,000$ & $\mathbf{0}$ & $\$ 163,539.13$ & Dominated & PED \\
\hline & $\$ 32,000$ & $\mathbf{0}$ & $\$ 102,211.41$ & Dominated & PED \\
\hline Initial procedural cost of endovascular coiling & $\$ 41,000$ & 0 & $\$ 40,883.69$ & Dominated & Coil \\
\hline & $\$ 50,000$ & Dominated & $\mathbf{0}$ & Dominated & Coil \\
\hline & $\$ 5,000$ & Dominated & $\mathbf{0}$ & Dominated & Coil \\
\hline & $\$ 14,000$ & 0 & $\$ 3,530.54$ & Dominated & Coil \\
\hline & $\$ 23,000$ & $\mathbf{0}$ & $\$ 64,858.98$ & Dominated & PED \\
\hline Probability of initial death after PED treatment & $\$ 32,000$ & $\mathbf{0}$ & $\$ 126,185.98$ & Dominated & PED \\
\hline & $\$ 50,000$ & $\mathbf{0}$ & $\$ 187,513.70$ & Dominated & PED \\
\hline & $1 \%$ & $\$ 248,841.42$ & Dominated & PED \\
\hline & $2 \%$ & $\mathbf{0}$ & Dominated & Dominated & PED \\
\hline & $3 \%$ & $\mathbf{0}$ & Dominated & Dominated & PED \\
\hline & $5 \%$ & $\mathbf{0}$ & $\$ 93,779,895.12$ & Dominated & PED \\
\hline
\end{tabular}

An ICER corresponding to 0 refers to a nondominated base value. An ICER is dominated if another treatment option can provide more QALYS at lower cost. Nondominated ICERs $<\$ 50,000$ were deemed cost-effective. Boldface type indicates cost-effectiveness.

aneurysm to improve both QOL and decrease health care costs across a lifetime.

This model has several limitations-the primary outcomes of this study are based on the assumptions of prior studies. Given that large or giant intracranial aneurysms may not always be amenable to surgical clipping, vessel sacrifice, and bypass, surgical options were not included in this model and were beyond the scope of this analysis. Most

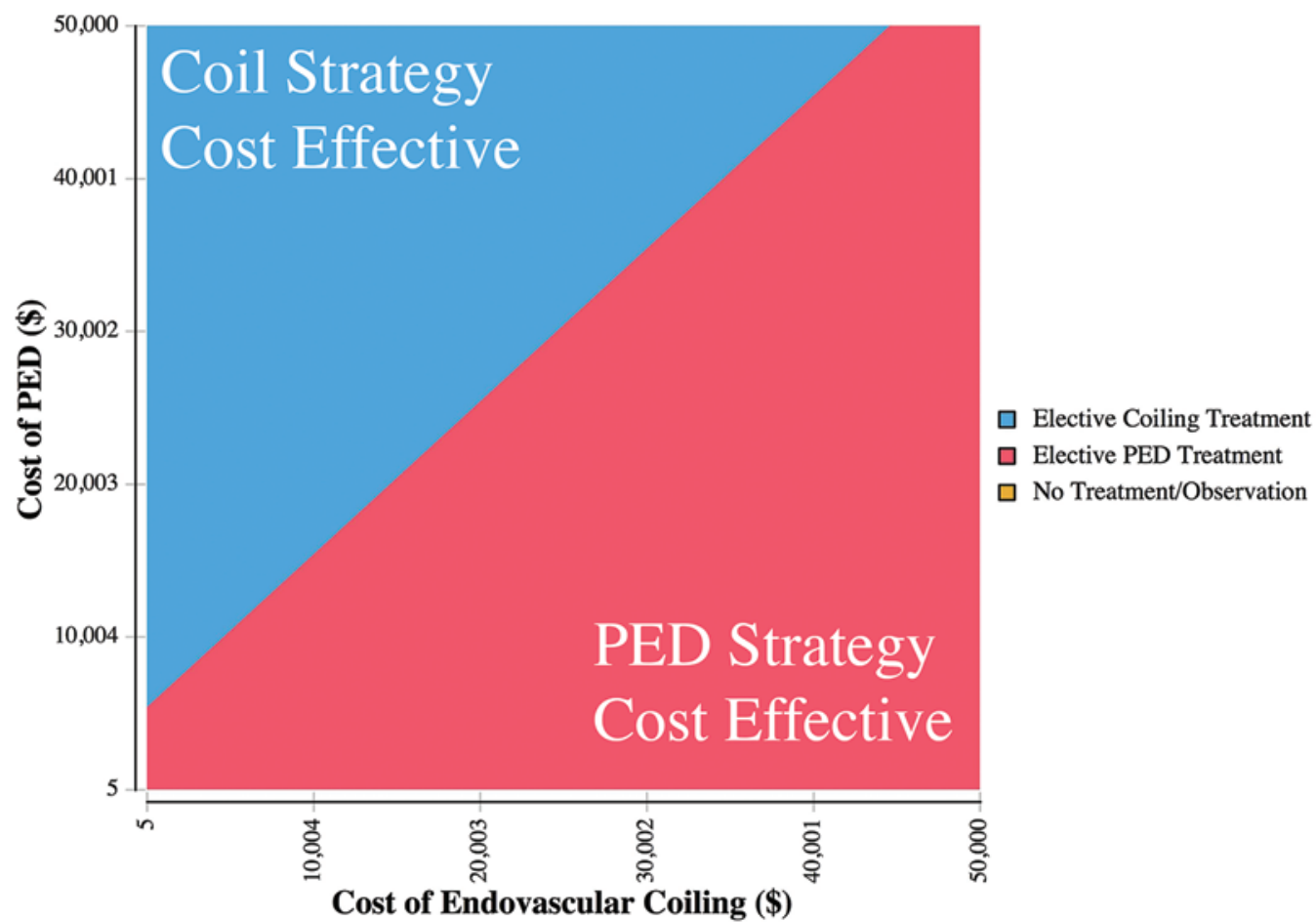

FIG. 3. Graph showing 2-way sensitivity analysis for the base-case scenario of PED treatment versus endovascular coiling versus no treatment as management plan for large or giant unruptured intracranial aneurysm. 




FIG. 4. Graph showing cost-effectiveness acceptability curve demonstrating that as the willingness to pay increases, PED is costeffective in $58.4 \%$ of iterations, coiling is cost-effective in $41.4 \%$ of iterations, and the no-treatment option is cost-effective in $0.2 \%$ of iterations.

of the model inputs were data obtained from retrospective single-center studies, due to the lack of randomized prospective data comparing the different endovascular techniques. The procedural costs in this model were derived from a single-center study and may not reflect costs in different clinical settings. However, our model addressed this limitation using 1- and 2-way sensitivity analyses to adjust procedural costs from $\$ 5000$ to $\$ 50,000$, and aggregated the costs of endovascular coiling with balloon-assisted coiling and stent-assisted coiling. Probabilities of technical success may also differ across surgeons and centers; we also addressed this using a 1-way sensitivity analysis. Our model does not include additional costs associated with endovascular complications, such as femoral hematoma, vessel vasospasm related to catheter procedures, or thromboembolic stroke. ${ }^{25}$ However, to address this limitation, our model captured complications as affecting QOL if they caused long-term disability or death. Although our model derived all neurological outcome probabilities and costs from the single existing comparative study assessing PED and endovascular coiling for large or giant aneurysm, these variables were consistent with those in larger, prospective studies comparing the efficacy of these techniques individually. Future cost-effectiveness studies comparing endovascular techniques may benefit from additional data on procedural costs, neurological and angiographic outcomes, and complication and retreatment rates from larger, prospective multicenter settings.

Despite these limitations, our model is the first costeffectiveness analysis that directly compares the elective endovascular management of large or giant intracranial aneurysms and provides an important perspective on the impact of aneurysm treatment on cost and health utilities. These findings should be considered in the setting of competing procedural options for a patient with a large or unruptured intracranial aneurysm to guide an informed decision that optimizes QOL and minimizes costs of intervention and rehabilitation.

\section{Conclusions}

Large or giant intracranial aneurysms pose a high risk of rupture-leading to expensive emergency treatments, reduction in QOL due to neurological disability, and a higher risk of death. Our cost-effectiveness model demonstrates that elective endovascular techniques such as PED and endovascular coiling are cost-effective strategies for improving health outcomes and lifetime QOL measures in patients with large or giant unruptured intracranial aneurysm.

\section{Acknowledgments}

Mr. Wali and Mr. Park are funded through NIH TL1 predoctoral grants (\#1TL1TR001443 and \#TL1TR00098, respectively).

\section{References}

1. Banks JL, Marotta CA: Outcomes validity and reliability of the modified Rankin scale: implications for stroke clinical trials: a literature review and synthesis. Stroke 38:10911096, 2007

2. Becske T, Kallmes DF, Saatci I, McDougall CG, Szikora I, Lanzino G, et al: Pipeline for uncoilable or failed aneurysms: results from a multicenter clinical trial. Radiology 267:858868,2013 
3. Becske T, Potts MB, Shapiro M, Kallmes DF, Brinjikji W, Saatci I, et al: Pipeline for uncoilable or failed aneurysms: 3 -year follow-up results. J Neurosurg [epub ahead of print October 14, 2016. DOI: 10.3171/2015.6.JNS15311]

4. Bliss CI, Fisher RA: Fitting the negative binomial distribution to biological data. Biometrics 9:176-200, 1953

5. Braithwaite RS, Meltzer DO, King JT Jr, Leslie D, Roberts MS: What does the value of modern medicine say about the $\$ 50,000$ per quality-adjusted life-year decision rule? Med Care 46:349-356, 2008

6. Chalouhi N, Tjoumakaris S, Starke RM, Gonzalez LF, Randazzo C, Hasan D, et al: Comparison of flow diversion and coiling in large unruptured intracranial saccular aneurysms. Stroke 44:2150-2154, 2013

7. Colby GP, Lin LM, Paul AR, Huang J, Tamargo RJ, Coon AL: Cost comparison of endovascular treatment of anterior circulation aneurysms with the pipeline embolization device and stent-assisted coiling. Neurosurgery 71:944-950, 2012

8. Concato J, Feinstein AR: Monte Carlo methods in clinical research: applications in multivariable analysis. J Investig Med 45:394-400, 1997

9. el-Chalouhi N, Jabbour PM, Tjoumakaris SI, Starke RM, Dumont AS, Liu H, et al: Treatment of large and giant intracranial aneurysms: cost comparison of flow diversion and traditional embolization strategies. World Neurosurg 82:696-701, 2014

10. Fischer S, Vajda Z, Aguilar Perez M, Schmid E, Hopf N, Bäzner H, et al: Pipeline embolization device (PED) for neurovascular reconstruction: initial experience in the treatment of 101 intracranial aneurysms and dissections. Neuroradiology 54:369-382, 2012

11. Gobin YP, Viñuela F, Gurian JH, Guglielmi G, Duckwiler GR, Massoud TF, et al: Treatment of large and giant fusiform intracranial aneurysms with Guglielmi detachable coils. J Neurosurg 84:55-62, 1996

12. Gruber A, Killer M, Bavinzski G, Richling B: Clinical and angiographic results of endosaccular coiling treatment of giant and very large intracranial aneurysms: a 7-year, singlecenter experience. Neurosurgery 45:793-804, 1999

13. Hunink MG: In search of tools to aid logical thinking and communicating about medical decision making. Med Decis Making 21:267-277, 2001

14. Ishibashi T, Murayama Y, Urashima M, Saguchi T, Ebara M, Arakawa H, et al: Unruptured intracranial aneurysms: incidence of rupture and risk factors. Stroke 40:313-316, 2009

15. Johnston SC, Dowd CF, Higashida RT, Lawton MT, Duckwiler GR, Gress DR: Predictors of rehemorrhage after treatment of ruptured intracranial aneurysms: the Cerebral Aneurysm Rerupture After Treatment (CARAT) study. Stroke 39:120-125, 2008

16. Li H, He XY, Li XF, Zhang X, Liu YC, Duan CZ: Treatment of giant/large internal carotid aneurysms: parent artery occlusion or stent-assisted coiling. Int J Neurosci 126:46-52, 2016

17. Malisch TW, Guglielmi G, Viñuela F, Duckwiler G, Gobin YP, Martin NA, et al: Intracranial aneurysms treated with the Guglielmi detachable coil: midterm clinical results in a consecutive series of 100 patients. J Neurosurg 87:176-183, 1997

18. Maud A, Lakshminarayan K, Suri MF, Vazquez G, Lanzino G, Qureshi AI: Cost-effectiveness analysis of endovascular versus neurosurgical treatment for ruptured intracranial aneurysms in the United States. J Neurosurg 110:880-886, 2009

19. Mawad ME, Cekirge S, Ciceri E, Saatci I: Endovascular treatment of giant and large intracranial aneurysms by using a combination of stent placement and liquid polymer injection. J Neurosurg 96:474-482, 2002

20. Molyneux AJ, Kerr RS, Birks J, Ramzi N, Yarnold J, Sneade M, et al: Risk of recurrent subarachnoid haemorrhage, death, or dependence and standardised mortality ratios after clipping or coiling of an intracranial aneurysm in the International Subarachnoid Aneurysm Trial (ISAT): long-term follow-up. Lancet Neurol 8:427-433, 2009

21. Molyneux AJ, Kerr RS, Yu LM, Clarke M, Sneade M, Yarnold JA, et al: International subarachnoid aneurysm trial (ISAT) of neurosurgical clipping versus endovascular coiling in 2143 patients with ruptured intracranial aneurysms: a randomised comparison of effects on survival, dependency, seizures, rebleeding, subgroups, and aneurysm occlusion. Lancet 366:809-817, 2005

22. Nelson RE, Saltzman GM, Skalabrin EJ, Demaerschalk BM, Majersik JJ: The cost-effectiveness of telestroke in the treatment of acute ischemic stroke. Neurology 77:1590-1598, 2011

23. Ogilvy CS, Carter BS: A proposed comprehensive grading system to predict outcome for surgical management of intracranial aneurysms. Neurosurgery 42:959-970, 1998

24. Rivero-Arias O, Ouellet M, Gray A, Wolstenholme J, Rothwell PM, Luengo-Fernandez R: Mapping the modified Rankin scale (mRS) measurement into the generic EuroQol (EQ-5D) health outcome. Med Decis Making 30:341-354, 2010

25. Ross IB, Dhillon GS: Complications of endovascular treatment of cerebral aneurysms. Surg Neurol 64:12-19, 2005

26. Sluzewski M, Menovsky T, van Rooij WJ, Wijnalda D: Coiling of very large or giant cerebral aneurysms: long-term clinical and serial angiographic results. AJNR Am J Neuroradiol 24:257-262, 2003

27. van Loon J, Waerzeggers Y, Wilms G, Van Calenbergh F, Goffin J, Plets C: Early endovascular treatment of ruptured cerebral aneurysms in patients in very poor neurological condition. Neurosurgery 50:457-465, 2002

28. Yu SCH, Kwok CK, Cheng PW, Chan KY, Lau SS, Lui WM, et al: Intracranial aneurysms: midterm outcome of pipeline embolization device - a prospective study in 143 patients with 178 aneurysms. Radiology 265:893-901, 2012

29. Yue W: Endovascular treatment of unruptured intracranial aneurysms. Interv Neuroradiol 17:420-424, 2011

\section{Disclosures}

Dr. Khalessi is a consultant for Medtronic.

\section{Author Contributions}

Conception and design: all authors. Acquisition of data: Wali, Park, Santiago-Dieppa, Murphy. Analysis and interpretation of data: all authors. Drafting the article: Khalessi, Wali, Park, Vaida, Murphy. Critically revising the article: all authors. Reviewed submitted version of manuscript: all authors. Approved the final version of the manuscript on behalf of all authors: Khalessi. Statistical analysis: Wali, Park, Murphy. Administrative/technical/ material support: all authors. Study supervision: all authors.

\section{Correspondence}

Alexander A. Khalessi, Department of Neurosurgery, University of California, San Diego, 200 West Arbor Dr., San Diego, CA 92103.email: akhalessi@ucsd.edu. 